The Lahore Journal of Economics

11 : 1 (Summer 2006) pp. 1-18

\title{
Exports, Productivity and Economic Growth in Pakistan: A Time Series Analysis
}

\section{Aurangzeb*}

\begin{abstract}
This paper investigates the relationship between exports and economic growth in Pakistan by utilizing the analytical framework put forward by Feder (1983). The hypothesis that marginal factor productivities are not equal in export and non-export sectors of the Pakistan economy is tested by using time series from 1973 to 2005. The estimation results indicate that marginal factor productivities are significantly higher in the export sector. Moreover, the difference seems to derive, in part, from inter-sectoral positive externalities generated by the export sector. In broad terms, therefore, the results of this study are supportive of the export oriented, outward-looking approach to trade relations adopted by policymakers over the past decade.
\end{abstract}

JEL Codes: F1; F21; O53

Keywords: Pakistan; exports; growth; marginal factor productivities; externalities

\section{Introduction}

The role of exports in the economies of developing countries has been examined in a wide range of empirical and theoretical studies. It goes back to the classical economic theories of Adam Smith and David Ricardo, who argued that international trade plays an important role in economic growth and there are economic gains from specialization. It has been commonly viewed that being a component of GDP, exports contribute directly to national income growth and are among the most important sources of foreign exchange earnings that ease the pressure on the balance of payments and generate employment opportunities. Moreover,

\footnotetext{
${ }^{*}$ Economist, Social Policy and Development Centre (SPDC), Karachi, Pakistan.
} 
it is also recognized that the exports sector contributes to GDP growth more than other sectors.

These indirect growth promoting effects of exports are discussed by a number of economists who have highlighted various beneficial aspects of exports, such as economies of scale, increased capacity utilization, productivity gains and greater product variety and the like. Furthermore, exposure to greater foreign competition generates improvements in exporters' performance, by eliminating organizational inefficiencies and raising growth either through learning from foreign rivals or through spillovers of technologies and knowledge. For instance, firms that participate in foreign markets are able to get access to technical expertise regarding product designs and production methods from their foreign buyers (see Clerides et. al. (1998), Egan and Mody (1992), Feder (1983), Krueger (1980), Balassa (1978), Bhagwati and Srinivasan (1978) and Keesing (1967, 1979)). The implication of the above discussion is that there are substantial differences in the export and non-export oriented industries, such that the former have higher factor productivity.

The existing empirical literature which tests the hypothesis that exports stimulate growth (the so-called export-led growth, ELG, hypothesis) is extensive. We have, therefore, limited our literature review by referring firstly to some of the highly influential studies that provide a useful framework for the analysis of the ELG hypothesis, secondly to the major studies for developing countries and thirdly to empirical studies.

There are several influential studies that provide a useful framework for analyzing the relationship between exports and economic growth, for example, Baldwin and Caves (1997), Rivera-Batiz and Romer (1991), Segerstrom, Anant and Dinopoulos (1990), and Grossman and Helpman (1990). The basic idea of these studies is that exports increase total factor productivity because of their impact on economies of scale and other externalities such as technology transfer, improving skills of workers, improving managerial skills, and increasing the productive capacity of the economy.

There are several studies, analyzing the role of exports in the economic growth for developing countries. Most of these studies conclude that there is a positive relationship between exports and economic growth, for example, Khalifa A1-Youssif (1997), Levin and Raut (1997), Balassa (1978, 1985), Bahmani-Oskoee and Alse (1993), Bahmani-Oskoee, Mohtadi and Shabsigh (1991), Chow (1987), Jung and Marshall (1985) and Ram (1985, 1987). The key factors used in these studies to analyze the export-growth 
relationship are the effects due to economies of scale, increased capacity utilization, productivity gains, and greater product variety.

The empirical studies that confirm the strong association between exports and economic growth can be divided into two groups. The first group use cross-country analysis, of which key contributions are: Edwards (1992), Lopez (1991), Sheehey (1990), Kunst and Marin (1989), Ram (1985), Kavoussi (1984), Feder (1983), Tyler (1981) and Michaely (1977). Most of the cross-country studies tend to confirm the importance of exports for developing nations. The second group analyzes the country specific experiences. Most of these studies conclude that there is a positive and significant relationship between export expansion and economic growth.

None of the above studies empirically investigate the indirect effects of exports on growth, except that of Feder (1983). He is the first one who explicitly describes these indirect effects and develops an analytical framework to test the productivity differentials and externalities between exports and non-exports sector. In this paper we utilized this frame work for Pakistan. To our knowledge there is no such study which empirically investigates the indirect effects of exports for the case of Pakistan. All the existing studies consider the direct relationship between export expansion and economic growth, for instance, Aurangzeb (2003) and Khan, Malik and Hasan (1995).

The main intention of this paper is to analyze the direct and indirect impacts of exports on Pakistan's economic growth during 1973 to 2005 using the analytical framework developed by Feder (1983). The rest of the paper is organized as follows. In section 2 we discuss the theoretical framework used in this paper. Section 3 provides a brief description of the data used in the analysis. Section 4 provides the summary of the findings and section 5 provides some conclusions.

\section{The Theoretical Framework}

This section presents the theoretical framework developed by Feder (1983) in order to study the effects of exports on economic growth. Let total production in the economy $Y_{t}$ be composed of exports $X_{t}$ and nonexports $\mathrm{N}_{\mathrm{t}}$. Hence, instead of an aggregate national production function, each of the two sectors' output is a function of the factors allocated to the sector (the characteristic that defines the division into sectors could be technological content or skill requirement, for details see the discussion in the introduction above). In addition, production in the non-export sector is affected by the volume of exports produced. This formulation represents the beneficial effects of exports on other sectors, such as the introduction of 
advanced production techniques, training of higher quality human resources suitable for sustained growth, development of efficient and internationally competitive management, etc. (for details see Keesing (1967)). These are referred to as external effects of exports on the non-exports sector, since they are not reflected in market prices.

The generic production function for the non-export sector including externality effects from the export sector is given as:

$$
N=F\left(K_{N}, L_{N}, X\right)
$$

where $K_{N}$ and $L_{N}$ are the stocks of capital and labor used in the nonexport sector, respectively ${ }^{1}$. Let the production function in the export sector be given as:

$$
X=G\left(K_{X}, L_{X}\right)
$$

where $K_{X}$ and $L_{X}$ are the stocks of capital and labor used in the export sector, respectively. Further assume that factor productivities differ between the export and non-export sector. We have already discussed the reasons for the productivity differential between the export and non-export sector.

Suppose that the ratio of respective marginal factor productivities in the two sectors deviate from unity by a factor $\delta$ i.e.

$$
\frac{G_{K}}{F_{K}}=\frac{G_{L}}{F_{L}}=1+\delta
$$

where the subscripts denote partial derivatives:

In the light of the discussion in the previous section we assume that $\delta>0$. However, the external effects of the export sector are not included in $\delta$.

Differentiate equations (1) and (2) w.r.t. time we get.

$$
\begin{aligned}
& \dot{N}=F_{K} \dot{K}_{N}+F_{L} \dot{L}_{N}+F_{X} \dot{X} \\
& \dot{X}=G_{K} \dot{K}_{X}+G_{L} \dot{L}_{X}
\end{aligned}
$$

\footnotetext{
${ }^{1}$ The assumption of unidirectional externality effects needs to be imposed in order to allow for the identification of the parameters in the model. Thus, for simplicity the externalities of the domestic sector in the export sector are abstracted from the modeling.
} 
where $\dot{K}_{N}, \dot{K}_{X}$ and $\dot{L}_{N}, \dot{L}_{X}$ are the sectoral changes in the stock of capital and labor respectively and $F_{X}$ describes the marginal externality effect of exports on the output of non-exports. implies.

If $\mathrm{Y}$ denotes the Gross Domestic Product then by definition $\mathrm{Y}=\mathrm{N}+\mathrm{X}$,

$$
\dot{Y}=\dot{N}+\dot{X}
$$

Using equations (4), (5) and (6) we get:

$$
\dot{Y}=F_{K} \dot{K}_{N}+F_{L} \dot{L}_{N}+F_{X} \dot{X}+G_{K} \dot{K}_{X}+G_{L} \dot{L}_{X}
$$

Equations (3) and (7) yield

$$
\dot{Y}=\left(\dot{K}_{N}+\dot{K}_{X}\right) F_{K}+\left(\dot{L}_{N}+\dot{L}_{X}\right) F_{L}+\delta\left(F_{K} \dot{K}_{X}+F_{L} \dot{L}_{X}\right)+F_{X} \dot{X}
$$

Define the total change in capital stock in the economy as $\dot{K}=\dot{K}_{N}+\dot{K}_{X}$ and the total change in labor $\dot{L}=\dot{L}_{N}+\dot{L}_{X}$ and using equations (3),(4) and (8) we get:

$$
\dot{Y}=F_{K} \dot{K}+F_{L} \dot{L}+\left[\frac{\delta}{(1+\delta)}+F_{X}\right] \dot{X}
$$

Dividing equation (9) by $\mathrm{Y}$ and substituting $\alpha=F_{K}\left(\frac{K}{Y}\right), \beta=F_{L}\left(\frac{L}{Y}\right)$ and $\gamma=\left[\frac{\delta}{(1+\delta)}+F_{X}\right]$ we get the following reduced form equation:

$$
\frac{\dot{Y}_{t}}{Y_{t}}=\alpha \frac{\dot{K}_{t}}{K_{t}}+\beta \frac{\dot{L}_{t}}{L_{t}}+\gamma\left(\frac{\dot{X}_{t}}{X_{t}}\right)\left(\frac{X_{t}}{Y_{t}}\right)
$$

\subsection{Computation of social marginal productivity of investment in exports $\left(\mathrm{TMPK}_{\mathrm{x}}\right)$}

TMPK $_{\mathrm{x}}$ is defined as the total increment to GDP brought about by a marginal increase in capital allocated to the export sector i.e.

$$
\operatorname{TMPK}_{X}=\frac{d Y}{d K_{X}}=\frac{\partial X}{\partial K_{X}}+\frac{\partial N}{\partial X} \frac{\partial X}{\partial K_{X}}
$$




$$
\begin{aligned}
& \operatorname{TMPK}_{X}=G_{K}+F_{X} G_{K} \\
& \operatorname{TMPK}_{X} / G_{K}=1+F_{X}
\end{aligned}
$$

Using equations (3) and (13) we get

$$
\left(T M P K_{X}-F_{K}\right) / G_{K}=F_{X}+\delta /(1+\delta)
$$

The above equation measures the difference between the marginal contributions to GDP of production factors in the two sectors, relative to the marginal contributions of these factors to the export sector's output. Now equation (10) is interpreted as: the growth of GDP comprises the contribution of factor accumulation (i.e. growth of capital and 1abor) and the gains because of reallocation of factors from the low productivity sector (non-exports) to the high real productivity sector (exports).

\subsection{Specifying the externality effect}

So far we are not able to decompose the factor productivity differential $\gamma$ into its components. In order to identify separately the intersectoral externality effect we assume that exports affect the production of non-exports with constant elasticity i.e.

$$
N=F\left(K_{N}, L_{N}, X\right)=X^{\theta} \Phi\left(K_{N}, L_{N}\right),
$$

where $\theta$ is a parameter. Differentiate equation $(15)$ w.r.t. $\mathrm{X}$ we get:

$$
F_{x}=\frac{\partial N}{\partial X}=\theta \frac{N}{X}
$$

Equation (10) can now be written as:

$$
\frac{\dot{Y}_{t}}{Y_{t}}=\alpha \frac{\dot{K}_{t}}{K_{t}}+\beta \frac{\dot{L}_{t}}{L_{t}}+\left[\frac{\delta}{1+\delta}+\theta \frac{N}{X}\right]\left(\frac{\dot{X}_{t}}{X_{t}}\right)\left(\frac{X_{t}}{Y_{t}}\right)
$$

Also,

$$
\theta \frac{N}{X}=\theta \frac{(1-X / Y)}{X / Y}=\frac{\theta}{X / Y}-\theta
$$

Equations (17) and (18) will produce another reduced from equation: 


$$
\frac{\dot{Y}_{t}}{Y_{t}}=\alpha \frac{\dot{K}_{t}}{K_{t}}+\beta \frac{\dot{L}_{t}}{L_{t}}+\left(\frac{\delta}{(1+\delta)}-\theta\right)\left(\frac{\dot{X}_{t}}{X_{t}}\right)\left(\frac{X_{t}}{Y_{t}}\right)+\theta\left(\frac{\dot{X}_{t}}{X_{t}}\right)
$$

Equations (10) and (19) are estimated for Pakistan using the OLS technique ${ }^{2}$.

\section{Data Description}

The data has been acquired from the various issues of the Economic Survey of Pakistan and Statistical Supplements published by the Ministry of Finance. The data are annual series covering time period the 1973-2005. The time series includes total employed labor, real GDP, real gross fixed capital formation, real physical capital and real exports. Capital is constructed using the perpetual inventory method. We construct the base year capital stock using an infinite sum series of investment prior to the first year, assuming that the growth rates of investment during 1973-2005 are good proxy for investment prior to the first year (see Robert and Feenstra, 2004).

\section{Empirical Findings}

\subsection{Empirical results without specifying externality}

Given the analytical framework described in section 2 and without considering the functional form of the externality of the export sector we estimate equation (10) by regressing the rate of growth of GDP on the rate of growth of capital, rate of growth of labor and the rate of growth of exports multiplied by exports share in GDP. Since most of the macroeconomic time series are non-stationary in levels, by using variables in growth form instead of levels we are also able to remove the problem of spurious regression that will arise from the presence of unit roots ${ }^{3}$. The results are reported in Table-1. The results provide strong support to the hypothesis that the marginal productivities in the export sector are higher than in the non-export sector, as the coefficient of $\left(\dot{X}_{t} / X_{t}\right)\left(X_{t} / Y_{t}\right)$ is positive and statistically significant. Furthermore, the capital share parameter $\alpha$ is statistically significant and exhibits the expected positive influence on growth. The results indicate that on average, exporters have significantly higher levels of productivity than non-exporters and exports contribute to growth mainly through increased productivity. This seems plausible and supports the view formalized by

\footnotetext{
${ }^{2}$ For detailed derivation see Appendix-I

${ }^{3}$ For unit root tests results see Table-2 in Appendix-I.
} 
Grossman and Helpman (1990) that competitive pressure on international markets improves efficiency in production and management procedures.

Table-1: OLS results (dependent variable is $\dot{Y}_{t} / Y_{t}$ )

\begin{tabular}{lccc}
\hline Variables & Parameters & Coeff. & t-stats \\
\hline Constant & $\mathrm{c}$ & 0.017 & 2.07 \\
$\dot{K}_{t} / K_{t}$ & $\alpha$ & 0.417 & 2.70 \\
$\left(\dot{X}_{t} / X_{t}\right)\left(X_{t} / Y_{t}\right)$ & $\gamma$ & 0.543 & 4.37 \\
& & & \\
$R^{2}=0.17$ & & \\
$\bar{R}^{2}=0.11$ & \\
$D W=1.6$ & \\
$A R C H$ & $F-$ stats $=0.12$ & $p-$ value $=0.73$ \\
\hline
\end{tabular}

\subsection{Empirical results after specifying externality}

The estimate of the $\gamma$ parameter obtained above provides the combined effect. In order to find the separate estimate for the intersectoral externality effect, we need to estimate equation (19). The OLS estimation of equation (19) is reported in Table-2(a). It is observed from the results in Table-2(a) that the $\theta$ parameter is statistically insignificant. This result could be because of high collinearnity between $\left(\dot{X}_{t} / X_{t}\right)\left(X_{t} / Y_{t}\right)$ and $\dot{X}_{t} / X_{t}$ regressors. (See the correlation matrix reported in Table- 1 in Appendix-I). Because of multicollinearity the standard errors of OLS estimators will become very large which results in insignificant t-ratios. Several methods have been developed as a remedy for multicollinearity. The one which is commonly used in the literature to solve the problem of multicollinearity is the ridge regression $(\mathrm{RR})$ technique. In $\mathrm{RR}$ we estimate $\hat{\beta}_{R R}=\left[X^{T} X+\lambda I\right]^{-1} X^{T} Y$ instead of $\hat{\beta}_{\text {OLS }}=\left[X^{T} X\right]^{-1} X^{T} Y$ as in OLS. By adding a small number $\lambda$ on the diagonal elements of the matrix to be inverted will yield an estimator having smaller mean square error than the ordinary least square estimators (for detail discussion about the RR estimator see Vinod (1977), Sundberg (1993). The results obtained from ridge regression (for $\lambda=0.012$ ) are reported in Table-2(b). The results indicate that the inter-sectoral externality parameter $\theta$ is statistically significant and the magnitude of the parameter is also quite substantial. If exports are growing by $10 \%$ without withdrawing resources from the non- 
export sector, the latter grows by approximately $0.6 \%$. The other component of the productivity differential $\delta$ can be calculated by using the estimated values of $\theta$ and $\gamma$. The result $\delta \cong 0.45$ implies that there is a substantial productivity differential between the export and non-export sectors in addition to the differential due to externalities in the case of Pakistan. The coefficient of the capital share parameter is also statistically significant, is within the expected range and has the expected sign. The expected range for the capital share parameter using a narrow concept of physical capital (structures and equipments) is $\alpha \leq 1 / 3$ (see Maddison (1982) and Jorgenson et. al. (1987)).

The results in this study appear consistent with the studies on other developing economies, by obtaining a significant external effect of the export sector on non-export sector (measured by the $\theta$ parameter). International spillovers arising from exports expand the stock of ideas that can be used for research in the domestic economy. Successful R\&D can then generate growth through expansion in the variety and quality of domestically produced goods and services. Moreover, they are also consistent with the argument that it is only the better performing firms that are able to enter international markets because they are the ones which are able to bear the more intense competitive pressure there (Tybout (2000)).

Table-2(a): OLS results (dependent variable is $\dot{Y}_{t} / Y_{t}$ )

\begin{tabular}{lccc}
\hline Variables & Parameters & Coeff. & t-stats \\
\hline Constant & $\mathrm{c}$ & 0.018 & 1.4 \\
$\dot{K}_{t} / K_{t}$ & $\alpha$ & 0.411 & 2.3 \\
$\left(\dot{X}_{t} / X_{t}\right)\left(X_{t} / Y_{t}\right)$ & $\gamma$ & 0.562 & 2.0 \\
$\dot{X}_{t} / X_{t}$ & $\theta$ & -0.004 & -0.1 \\
& & & \\
$R^{2}=0.17$ & & & \\
$\bar{R}^{2}=0.10$ & & & \\
$D W$ & & & \\
$A R C H$ & $F-$ stats $=0.13$ & $p-$ value $=0.71$ \\
\hline
\end{tabular}

Table-2(b): Ridge regression results (dependent variable is $\dot{Y}_{t} / Y_{t}$ ) 


\begin{tabular}{lccc}
\hline Variables & Parameters & Coeff. & t-stats \\
\hline Constant & $\mathrm{c}$ & 0.01 & 1.96 \\
$\dot{K}_{t} / K_{t}$ & $\alpha$ & 0.32 & 2.72 \\
$\left(\dot{X}_{t} / X_{t}\right)\left(X_{t} / Y_{t}\right)$ & $\gamma$ & 0.25 & 1.75 \\
$\dot{X}_{t} / X_{t}$ & $\theta$ & 0.06 & 1.65 \\
$R^{2}=0.61$ & & & \\
$\bar{R}^{2}=0.57$ & & \\
$D W=1.9$ & & \\
$A R C H$ & $F-$ stats $=0.11$ & $p-$ value $=0.73$ \\
\hline
\end{tabular}

\subsection{Sources of growth:}

Using the results reported in Table-2(b) and averages of the explanatory variables, the average rate of GDP growth over the period of 1973 2005 can be decomposed so as to identify the contribution of each factor. The computation and the results are reported in Table- 3 . The results indicate that the re-allocation of resources associated with export expansion contributed approximately 0.9 percentage points to the overall growth of the economy (4.9\%). This gain because of exports comprises two components: (i) gain due to beneficial externalities affecting the non-export sector and (ii) gain due to other factors such as higher productivity in the exports sector.

Table-3: Factors Contributing in Growth over the Period 1973-2005

\begin{tabular}{lcccc}
\hline \multicolumn{1}{c}{ Variables } & Averages & Parameters & Coefficients $\begin{array}{c}\text { Contribution } \\
\text { to Growth } \\
{[(1) \times(2)] \times 100}\end{array}$ \\
\hline$\dot{K}_{t} / K_{t}$ & 0.0651 & $\alpha$ & 0.32 & 2.083 \\
$\left(\dot{X}_{t} / X_{t}\right)\left(X_{t} / Y_{t}\right)$ & 0.0228 & $\gamma$ & 0.25 & 0.569 \\
$\dot{X}_{t} / X_{t}$ & 0.0546 & $\theta$ & 0.06 & 0.328 \\
$\dot{L}_{t} / L_{t}$ & 0.0249 & $1-(\alpha+\gamma+\theta)$ & 0.37 & 0.920 \\
Constant & & $c$ & 0.01 & 1.000 \\
GDP Growth $\dot{Y}_{t} / Y_{t}$ & 0.049 & & & 4.9 \\
\hline
\end{tabular}




\section{Conclusion}

The purpose of this study was to test the applicability of the hypothesis that export expansion would increase economic growth using the framework developed by Feder (1983) for Pakistan during the period 1973 to 2005 . Moreover, the empirical evidence presented in this paper allows us to draw some conclusions on the mechanism through which exports affect economic growth. In conclusion, we can say that in Pakistan gains from increased openness on the export side is primarily via improved resource allocation, which is itself an outcome of greater exposure to international competition. This efficient use of available resources increases the productivity in the export sector more than the non-export sector. Furthermore, learning effects and other positive externalities are also found to be influential for the performance of the non-export sector and thus, improve the overall level of welfare and growth of the economy.

The results are such that social marginal productivities are higher in the export sector, and an outward-looking strategy which shift resources into exports will result in higher growth than an inward-looking strategy. Hence, an export-oriented, outward-looking approach is required if Pakistan wishes to pursue high rates of economic growth, which can also be observed in the success story of export-led economies such as Korea. 


\section{Appendix I}

Feder's (1982) Approach:

$$
\begin{aligned}
& N=F\left(K_{n}, L_{n}, X\right) \\
& X=G\left(K_{x} L_{x}\right) \\
& Y=N+X
\end{aligned}
$$

where,

$$
\begin{aligned}
& N=\text { Non }- \text { exports } \\
& X=\text { Exports }
\end{aligned}
$$

Assumption:

$$
\begin{aligned}
& G_{K} / F_{K}=G_{L} / F_{L}=1+\delta \\
& \text { Eq.(1),(2),(3) } \Rightarrow \\
& \dot{Y}=F_{K} \dot{K}_{n}+F_{L} \dot{L}_{n}+F_{x} \dot{X}+G_{K} \dot{K}_{x}+G_{L} \dot{L}_{x} \\
& \text { Eq.(4) } \Rightarrow \\
& G_{K}=(1+\delta) F_{K} ; G_{L}=(1+\delta) F_{L}
\end{aligned}
$$

(5)and (6) $\Rightarrow$

$$
\dot{Y}=\left(\dot{K}_{n}+\dot{K}_{x}\right) F_{K}+\left(\dot{L}_{n}+\dot{L}_{x}\right) F_{L}+g\left(F_{K} \dot{K}_{x}+F_{L} \dot{L}_{x}\right)+F_{x} \dot{X}
$$

Also,

$$
\begin{aligned}
& F_{L}=\frac{1}{(1+\delta)} G_{L} ; F_{K}=\frac{1}{(1+\delta)} G_{K} \\
& \dot{X}=G_{K} \dot{K}_{x}+G_{L} \dot{L}_{x} \\
& \text { Eq.(7), (8),(9) } \Rightarrow \\
& \dot{Y}=F_{K} \dot{K}+F_{L} \dot{L}+\left[\frac{\delta}{(1+\delta)}\right] \dot{X}+F_{x} \dot{X} \\
& \dot{Y}=F_{K} \dot{K}+F_{L} \dot{L}+\left[\frac{\delta}{(1+\delta)}+F_{x}\right] \dot{X}
\end{aligned}
$$


Hence the reduced form Equation is given as

$$
\frac{\dot{Y}_{t}}{Y_{t}}=\alpha \frac{\dot{K}_{t}}{K_{t}}+\beta \frac{\dot{L}_{t}}{L_{t}}+\gamma\left(\frac{\dot{X}_{t}}{X_{t}}\right)\left(\frac{X_{t}}{Y_{t}}\right)
$$

Where,

$$
\gamma=\left[\frac{\delta}{(1+\delta)}+F_{x}\right]
$$

Computation of social marginal productivity of investment in Exports $\left(\mathrm{TMPK}_{\mathrm{x}}\right)$

$$
\begin{aligned}
& \operatorname{TMPK}_{x}=\frac{d Y}{d K_{x}}=\frac{\partial X}{\partial K_{x}}+\frac{\partial N}{\partial X} \frac{\partial X}{\partial K_{x}} \\
& T M P K_{x}=G_{K}+F_{x} G_{K} \\
& T M P K_{x} / G_{K}=1+F_{x} \\
& \operatorname{Recall} \quad E q \\
& G_{K} / F_{K}=1+\delta
\end{aligned}
$$

Hence,

$$
\begin{aligned}
& 1-F_{K} / G_{K}=\delta /(1+\delta) \\
& (15) \operatorname{and}(16) \Rightarrow \\
& \operatorname{TMPK}_{x} / G_{K}+1-F_{K} / G_{K}=1+F_{x}+\delta /(1+\delta) \\
& \left(T M P K_{x}-F_{K}\right) / G_{K}=F_{x}+\delta /(1+\delta)
\end{aligned}
$$

\section{External effect of export on non-export sector $\left(F_{x}\right)$}

$$
\begin{aligned}
& N=F\left(K_{n}, L_{n}, X\right)=X^{\theta} \Phi\left(K_{n}, L_{n}\right) \\
& F_{x}=\frac{\partial N}{\partial X}=\theta \frac{N}{X}
\end{aligned}
$$

Aside

$$
\theta \frac{N}{X}=\theta\left(\frac{N / Y}{X / Y}\right)
$$


where

$$
\begin{aligned}
N / Y & =1-X / Y \\
\Rightarrow & \\
\theta \frac{N}{X} & =\theta \frac{(1-X / Y)}{X / Y}=\frac{\theta}{X / Y}-\theta \\
E q(12),(18) & \Rightarrow \quad \text { another reduced form Equation } \\
\frac{\dot{Y}_{t}}{Y_{t}} & \alpha \frac{\dot{K}_{t}}{K_{t}}+\beta \frac{\dot{L}_{t}}{L_{t}}+\left(\frac{\delta}{(1+\delta)}-\theta\right)\left(\frac{\dot{X}_{t}}{X_{t}}\right)\left(\frac{X_{t}}{Y_{t}}\right)+\theta\left(\frac{\dot{X}_{t}}{X_{t}}\right)
\end{aligned}
$$

Hence;

$$
\begin{aligned}
& \operatorname{TMPK}_{x}=F_{K}\left[1+\theta\left(\frac{1-x}{x}\right)\right](1+\delta) \\
& \operatorname{TMPK}_{x}=\alpha\left[1+\theta\left(\frac{1-x}{x}\right)\right](1+\delta)
\end{aligned}
$$

Where $\mathrm{x}=$ share of exports in GDP

\section{Reduced from equations}

$$
\begin{aligned}
& \frac{\dot{Y}_{t}}{Y_{t}}=\alpha \frac{\dot{K}_{t}}{K_{t}}+\beta \frac{\dot{L}_{t}}{L_{t}}+\gamma\left(\frac{\dot{X}_{t}}{X_{t}}\right)\left(\frac{X_{t}}{Y_{t}}\right) \\
& \frac{\dot{Y}_{t}}{Y_{t}}=\alpha \frac{\dot{K}_{t}}{K_{t}}+\beta \frac{\dot{L}_{t}}{L_{t}}+\left(\frac{\delta}{(1+\delta)}-\theta\right)\left(\frac{\dot{X}_{t}}{X_{t}}\right)\left(\frac{X_{t}}{Y_{t}}\right)+\theta\left(\frac{\dot{X}_{t}}{X_{t}}\right)
\end{aligned}
$$

The above equations are estimated by using OLS

$$
\begin{aligned}
& \frac{\dot{Y}_{t}}{Y_{t}}=\hat{\alpha} \frac{\dot{K}_{t}}{K_{t}}+\hat{\beta} \frac{\dot{L}_{t}}{L_{t}}+\hat{\gamma}\left(\frac{\dot{X}_{t}}{X_{t}}\right)\left(\frac{X_{t}}{Y_{t}}\right)+\varepsilon_{t} \\
& \frac{\dot{Y}_{t}}{Y_{t}}=\hat{\alpha} \frac{\dot{K}_{t}}{K_{t}}+\hat{\beta} \frac{\dot{L}_{t}}{L_{t}}+\hat{\xi}\left(\frac{\dot{X}_{t}}{X_{t}}\right)\left(\frac{X_{t}}{Y_{t}}\right)+\hat{\theta}\left(\frac{\dot{X}_{t}}{X_{t}}\right)+v_{t}
\end{aligned}
$$

Where,

$$
\hat{\xi}=\left(\frac{\delta}{(1+\delta)}-\theta\right)
$$


Table-1: Correlation Matrix

\begin{tabular}{lccc}
\hline & $\dot{K}_{t} / K_{t}$ & $\left(\dot{X}_{t} / X_{t}\right)\left(X_{t} / Y_{t}\right)$ & $\dot{X}_{t} / X_{t}$ \\
$\dot{K}_{t} / K_{t}$ & 1 & 0.58 & 0.26 \\
$\left(\dot{X}_{t} / X_{t}\right)\left(X_{t} / Y_{t}\right)$ & 1 & 0.81 \\
$\dot{X}_{t} / X_{t}$ & & 1 \\
\hline
\end{tabular}

Table-2: Unit root tests results

\begin{tabular}{lcccccc}
\hline Variables & \multicolumn{2}{c}{ ADF } & \multicolumn{2}{c}{ PP } & \multicolumn{2}{c}{ KPSS } \\
\cline { 2 - 7 } & Level & $\begin{array}{c}\text { First } \\
\text { Difference }\end{array}$ & Level & $\begin{array}{c}\text { First } \\
\text { Difference }\end{array}$ & Level & $\begin{array}{c}\text { First } \\
\text { Difference }\end{array}$ \\
\hline $\mathbf{y}_{\mathbf{t}}^{\mathbf{r}}$ & -1.56 & -3.70 & -1.30 & -3.71 & 0.66 & 0.27 \\
$\mathbf{k}_{\mathbf{r}}^{\mathbf{r}}$ & -0.49 & -2.80 & 9.02 & -3.68 & 0.21 & 0.08 \\
$\mathbf{x}_{\mathbf{r}}^{\mathbf{r}}$ & 0.21 & -5.49 & 0.17 & -5.49 & 0.64 & 0.13 \\
\hline
\end{tabular}

Notes: Critical values for Augmented Dicky-Fuller (ADF) and Phillips-Perron (PP) tests are -2.96 and -2.61 at $5 \%$ and $10 \%$ significance leve1 respectively. Critical values for Kwiatkowski-Phillips-Schmidt-Shin (KPSS) test are 0.46 and 0.35 at $5 \%$ and $10 \%$ significance leve1 respectively. 


\section{References}

Aurangzeb, 2003, "Trade, Investment and Growth Nexus in Pakistan: an Application of Co-integration and Multivariate Causality Test”, The Lahore Journal of Economics, Vol. 8(1).

Balassa, B., 1978, "Exports and Economic Growth: Further Evidence" Journal of Development Economics, Vol. 5.

Balassa, B., 1985, "Exports Policy Choices and Economic Growth in Developing Countries after the 1973 Oil Shocks”, Journal of Development Economics, Vo1. 18.

Baldwin, J. and Caves, R., 1997, "International competition and industrial performance: allocative efficiency, productive efficiency and turbulence”, Harvard Economics Discussion Paper No. 1809.

Bahmani-Oskoee M., H. Mohtadi and G. Shabsigh, 1991, "Exports, Growth and Causality in LDCs: A Re-examination", Journal of Development Economics, Vo1. 36.

Bahmani-Oskoee, M and J. Alse, 1993, "Export Growth and Economic Growth: An Application of Cointegration and Error-Correction Mode1ling”, Journal of Development Areas, Vo1. 27.

Bhagwati J.N. and T.N. Srinivasan, 1978, "Trade Policy and Development, in: Rudiger Dornbusch and Jacob A. Frenke1, eds., International Economic Policy: Theory and Evidence ch. 1, John Hopkins University Press, Baltimore, MD.

Chow, P.C. Y., 1987, "Causality between Export Growth and Industrial Development”, Journal of Development Economics, Vo1. 26.

Clerides, S.K., Laul, S. and Tybout, J.R., 1998, "Is learning by exporting important? Micro-dynamic evidence from Columbia, Mexico and Morocco”, Quarterly Journal of Economics, Vo1. CXIII.

Economic Survey, various issues, Ministry of Finance, Pakistan.

Edwards, S., 1992, "Trade Liberalization and Growth in Developing Countries” Journal of Development Economics, Vol. 39. 
Egan, M.L. and Mody, A., 1992, "Buyer-seller links in export development", World Development, Vol. 20.

Feder, G., 1983, “On Exports and Economic Growth”, Journal of Development Economics, Vo1. 12.

Grossman, G.M. and E. Helpman, 1990, "Comparative Advantage and Long Run Growth”, American Economic Review, Vol. 80.

Jung, W.S. and P.J. Marshall, 1985, "Exports, Growth and Causality in Developing Countries”, Journal of Development Economics, Vo1. 18.

Jorgensen, D.W., Frank, M.G. and Barbara, M.F., 1987, Productivity and U.S. Economic growth, Harvard University Press, Cambridge MA.

Khalifa A1-Youssif Y., 1997, "Exports and Growth: Some Empirical Evidence from the Arab Gulf States”, Applied Economics, Vol. 29.

Kavoussi, R.M., 1984, "Export Expansion and Economic Growth: Further Empirical Evidence”, Journal of Development Economics, Vo1. 14.

Khan, A.H. Malik, A. and Hasan, L., 1995, "Exports, Growth and Causality: An Application of Co-Integration and Error-Correction Modeling”, Pakistan Development Review, Vo1. 34(4).

Kunst, R.M. and Marin, D., 1989, "On Exports and Productivity: A Causal Analysis”, Review of Economics and Statistics, Vo1. 71.

Kruger, A.O., 1980, "Trade Policy as an Input to Development", American Economic Review, Vol. 70(2).

Keesing D.B., 1967, “Outward-Looking Policies and Economic Development”, Economic Journal, Vol. 77(36).

Keesing D.B., 1979, “Trade Policy for Developing Countries”, World Bank Staff Working Paper, No. 353.

Levin, A. and L.K. Raut, 1997, "Complementarities between Exports and Human Capital: Evidence from the Semi-Industrialized Countries", Economic Development and Cultural Change, Vo1. 46.

Lopez, R., 1991, "How Trade and Macroeconomic Policies Affect Economic Growth and Capital Accumulation in Developing Countries", Policy Research Working Paper, No. 625, Washington, DC: World Bank. 
Maddison, A., 1982, Phases of Capitalist Development, Oxford University Press, Oxford.

Michaely, M., 1977, "Exports and Growth: An Empirical Investigation", Journal of Development Economics, Vol. 4.

Rivera-Batiz, L.A. and P.M. Romer, 1991, "Economic Integration and Endogenous Growth”, Quarterly Journal of Economics, Vol. 206.

Ram, R., 1985, "Exports and Economic Growth: Some Additional Evidence" Economic Development and Cultural Change, Vo1. 33.

Ram, R., 1987, "Exports and Economic Growth: Evidence from Time-Series and Cross-Section Data”, Economic Development and Cultural Change, Vol. 36.

Robert, C. and H.L.K. Feenstra, 2004, "Export Variety and Country Productivity”, National Bureau of Economic Research, Working Paper No. 10830.

Segerstrom, P.C., T.C.A. Anant; and E. Dinopoulos, 1990, "A Schumpeterian Model of the Product Life Cycle”, American Economic Review, Vol. 80: 1077-1091.

Sheehey, E., 1990, "Exports and Growth: A Flawed Framework", Journal of Development Studies, Vol. 27: 111-116.

Srinivasan, T.N. and J. Bhagwati, 2001, "Outward Orientation and Development: Are Revisionist Right?” in D. Lai and H. Snape (eds), Trade, Development and Political Economy (Essays in Honor of Anne O. Krueger), New York: Palgrave Publishers.

Sundberg, R., 1993, “Continuum Regression and Ridge Regression”, Journal of Statistical Society, Vol. 55.

Tybout, J., 2000, "Manufacturing Firms In Developing Countries: How Well Do They Do And Why?", Journal of Economic Literature, Vol. XXXVIII.

Tyler W.G., 1981, "Growth and Export Expansion in Developing Countries: Some Empirical Evidence”, Journal of Development Economics, Vol. 9. 
Vinod H.D., 1978, “A Survey of Ridge Regression and Related Techniques for Improvements over Ordinary Least Squares", Review of Economics and Statistics Vo1. 60. 